\title{
Sliding Mode Fixed Frequency Current Controller Design for Grid-Connected NPC Inverter
}

\author{
Fadia Sebaaly, Student, IEEE, Hani Vahedi, Student, IEEE, \\ Hadi Y. Kanaan, Senior Member, IEEE, Nazih Moubayed, and Kamal Al-Haddad, Fellow, IEEE
}

\begin{abstract}
In this paper, a fixed-frequency pulse width modulation (PWM) based on sliding-mode current controller (SMCC) is designed and applied to a utility interface threephase/wire/level Neutral-Point-Clamped (NPC) inverter. The proposed design methodology of the SMC is based on a constant switching frequency operation and on Gao's reaching law that allows chattering compensation. The aim of the controller is to inject a controlled active power from renewable energy sources into the grid while controlling the power factor and minimizing supply current harmonics. Moreover, the DC-link voltages across the split capacitors are controlled with a simple proportional -integral (PI) regulator. Experimental results show the advantages of the proposed control algorithm in terms of fast dynamic response, low voltage ripple on the dc bus, low current THD, and robustness towards external perturbations from DC and AC sides, moreover a comparison with a PWM-PI current controller is presented.
\end{abstract}

Keywords-Sliding-mode control, three-phase neutral-pointclamped inverter, active rectifier, NPC, active filters, hybrid filters.

\section{INTRODUCTION}

$\mathrm{T}$ $\mathrm{HE}$ increasing use of multilevel inverters in renewable energy conversion applications is mainly due to their inherent harmonic reduction ability, operation at low switching frequency, and their capacity to deliver high power ratings which result in high penetration of sustainable energy resources such as wind and solar. Nowadays, power electronics devices are used as the interfacing part in sustainable power generation systems [1,2]. The increasing request for high quality electric energy in modern and smart grids has pushed the researchers to focus more on multilevel power converter topologies and to spend great efforts in developing their structure and control circuits.

Manuscript received December 31, 2015; revised March 13, 2016, and June 3, 2016; accepted June 22, 2016. This work has been supported by the Agence Universitaire de la Francophonie (AUF), the Lebanese National Council for Scientific Research (CNRS-L), The Research Council of Saint Joseph University, the Canadian Research Chair in Electric Energy Conversion and Power Electronics (CRC-EECPE) and the Natural Sciences and Engineering Research Council of Canada (NSERC).

F. Sebaaly and H.Y. Kanaan are with the Saint Joseph University of Beirut, Faculty of Engineering-ESIB, Beirut 1107-2050, Lebanon (e-mail: fadia_sebaaly@hotmail.com, hadi.kanaan@usj.edu.lb)

H. Vahedi and K. Al-Haddad are with the Ecole de Technologie Superieure, University of Quebec, Montreal, Quebec, Canada H3C 1K3 (email: hani.vahedi@etsmtl.ca,kamal.al-haddad@etsmtl.ca

N. Moubayed is with the Lebanese University-Faculty of Engineering, Tripoli, 310, Lebanon (email:nmoubayed@ieee.org).
Combination of power semi-conductor switches and DC links that generate multi-step voltage waveform is a main contribution in the multilevel topologies design [3, 4]. Many advantages of grid-connected multilevel inverters have been reported by researches [5-8].

Neutral-Point-Clamped (NPC) [9], Flying-Capacitor (FC) [10] and Cascaded H-Bridge (CHB) [11] are the most common topologies in multilevel inverters that have been built by manufacturing companies. Used as utility interface for renewable energy conversion systems, the three-level neutral-point-clamped inverter (3L-NPC) is the most attractive topology because of smaller size DC buses for the three-leg/phase topologies [12-18].

The major requirements for a current controller can be described as follows: 1) provide an ideal tracking, fast dynamic response and high utilization of the DC link voltage, 2) ensure a low current THD, and finally 3) allow a constant switching frequency for safety purposes and low switching losses. Many current control techniques were proposed for three-phase grid-connected inverters [19]. Among the proposed approaches, the nonlinear techniques show better performance against system uncertainties. Among nonlinear control techniques Sliding Mode Control (SMC) proved to be one of the most cost-effective methods due to its robustness, stability, good dynamic response and its high compatibility with the inherent switching nature of power converters [2023]. Due to its advantages, SMC was adopted not only in electric drives systems for direct torque control [24, 25] but also in inverters interfacing renewable energy sources such as wind energy systems [25, 26] and fuel cell applications [27].

In spite of its advantageous performance, SMC suffers from chattering problem with leads to variable and high switching frequency that leads to high power losses and considered to be highly control-sensitive to noise. For this purpose solutions have proposed the introduction of constant timers in the hysteretic module of SM controller [28] or the adoption of an adaptive hysteresis band that varies the parameter changes to fix the switching frequency [29]. Lately, a combination of a variable hysteresis band and switching decision (SDA) algorithms that ensure switching spectrum concentrated around the desired switching frequency is presented in [30] . However, all these solutions requires additional control components or extra input voltage. 


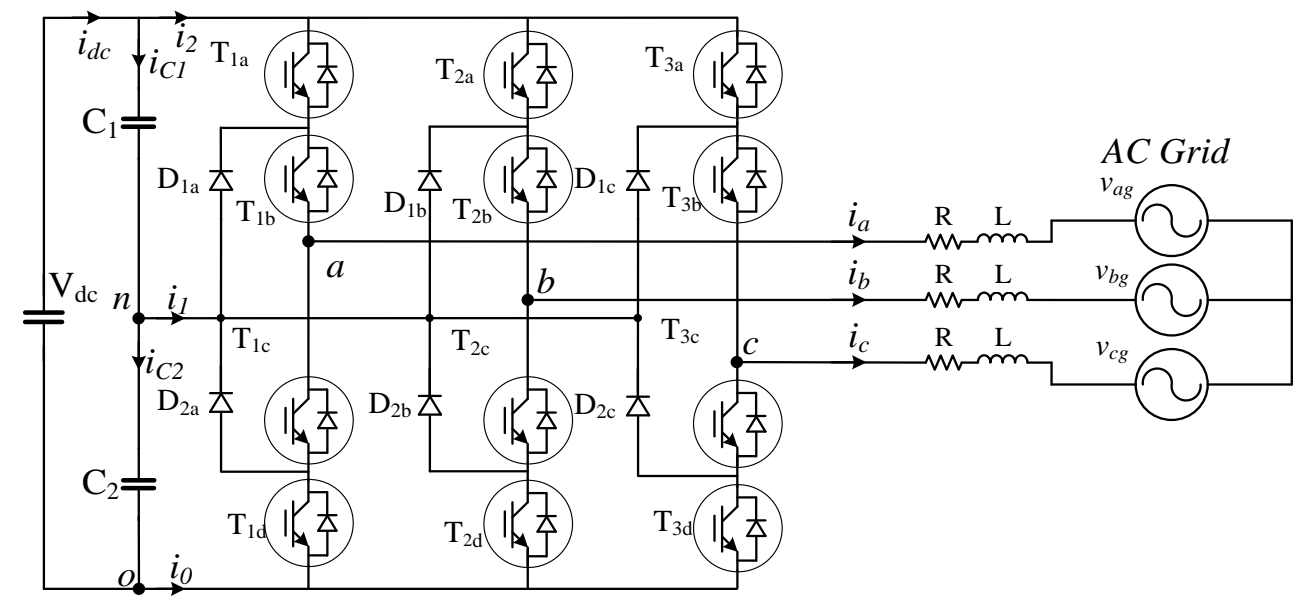

Fig. 1. Three-phase/wire/level NPC grid connected inverter as electric energy conversion system.

Another solution to operate at a constant switching frequency is by employing a pulse width modulator that uses an equivalent control law derived from the SM control. This law is used as a control signal compared to a fixed-frequency ramp in the modulator. Its main advantage is that the frequency of the output signal is kept constant regardless of the control signal variation. In literature, the design of a PWM-based SM controller was presented for buck converters [31], single phase unipolar inverters [32], DC-DC converters [33].

For grid connected inverters, studies focused on direct power (DP) based SM on two-level inverters [34, 35] and multilevel inverter [36]. Fewer attempts have adopted the SM method as a current control [30]. Besides, compliance with grid requirements in literature is not almost achieved where harmonic content of the current delivered to the grid is still relatively high. It can be concluded that even though the previous studies on the topic provide details on SM controllers for grid connected inverters, however they lack the full design and implementation of a PWM- based SM control for 3L-NPC grid connected inverter.

In this paper, we present the design of a fixed-frequency PWM-based SM current controlled NPC inverter in grid connection operation. Chattering compensation is done by the adoption of Gao's reaching law [37]. The advantages of the proposed controller are: 1) compliance with the grid requirements without the use of bulky filters at the output of NPC inverter, 2) accurate tracking response, 3) low THD and low ripple for the injected currents and synchronization with the grid voltage, and 4) stabilized DC bus voltage as well as output voltages under external perturbations. The performance and robustness of the proposed control system are tested and compared to a conventional PI-PWM regulator on a laboratory prototype of the NPC inverter. The obtained experimental results confirm the above-mentioned benefits of the proposed control technique.

The paper is divided as follows: in Section II, the mathematical model of the three-wire 3L-NPC grid connected inverter is presented; section III details the proposed slidingmode control algorithm, while the experimental results are discussed in section IV. Finally, section V concludes the study.

\section{The Three LeVEl NeUtral POINT Clamped GRID CONNECTED INVERTER}

Renewable energy sources are harvested using appropriate power electronic converters aimed to maximize power transfer between these sources and a common regulated DC bus. The energy transfer between the multiple energy sources and the utility is assumed by the 3L-NPC grid converter which regulates the dc bus voltage at a set point ensuring efficient and well-regulated high quality power transfer between fluctuating sources and the grid. The 3L-NPC multilevel inverter has been introduced in [5] as a three-leg topology with four power switches and two clamping diode in each leg, and split DC-bus capacitors. This inverter, depicted in Fig. 1, showed lower stress on the semiconductors devices by reducing the voltage at its terminals. Its main drawback is the balancing issue between upper and lower DC-link capacitors voltages. As seen from the switching states, switches $(1,3)$ or $(2,4)$ in each leg are complementary. Table 1 gives the output voltage between phase $a$ and the capacitors midpoint, for each combination of the switching states. The same values are obtained for the other two phases (b and c). The zero-voltage level obtained by this structure is the main factor in increasing the number of output voltage levels, which leads to a lower voltage harmonics content.

TABLE I

SWITCHING STATES OF PHASE A IN 3L-NPC INVERTER

\begin{tabular}{cccccc}
\hline \hline $\begin{array}{c}\text { Switching } \\
\text { function }\end{array}$ & \multicolumn{3}{c}{ Switching states } & & $\begin{array}{c}\text { Output } \\
\text { Voltage }\end{array}$ \\
$\boldsymbol{u}_{\boldsymbol{a}}$ & $\boldsymbol{T}_{\mathbf{1} \boldsymbol{a}}$ & $\boldsymbol{T}_{\boldsymbol{2} \boldsymbol{a}}$ & $\boldsymbol{T}_{\boldsymbol{3} \boldsymbol{a}}$ & $\boldsymbol{T}_{\boldsymbol{4} \boldsymbol{a}}$ & $\boldsymbol{V}_{\boldsymbol{a n}}$ \\
\hline+1 & 1 & 1 & 0 & 0 & $+\mathrm{V}_{\mathrm{dc}} / 2$ \\
0 & 0 & 1 & 1 & 0 & 0 \\
-1 & 0 & 0 & 1 & 1 & $-\mathrm{V}_{\mathrm{dc}} / 2$ \\
\hline \hline
\end{tabular}


The dynamic model of the system in Fig. 1 is given in the stationary reference frame as:

$$
\begin{aligned}
& L \frac{d i_{a b c}}{d t}=-R i_{a b c}+v_{a b c}-v_{g, a b c} \\
& v_{a b c}=\frac{V_{d c}}{3}\left[\begin{array}{ccc}
2 & -1 & -1 \\
-1 & 2 & -1 \\
-1 & -1 & 2
\end{array}\right] u_{a b c}
\end{aligned}
$$

Where $i_{a b c}$ are the grid currents, $v_{a b c}$ represent the inverter output voltages, $v_{g, a b c}$ the grid voltages, $u_{a b c}$ the switching function defined in Table I for each configuration, $V_{d c}$ the DCbus voltage, $R$ and $L$ the line resistor and inductor, respectively.

For a simpler design of the control system and for better tracking performance, the $d q$-model of the system is considered. It is obtained through a transformation from the stationary to a synchronous rotating frame using the following matrix:

$T=\sqrt{\frac{2}{3}}\left[\begin{array}{ccc}\cos \theta & \cos \left(\theta-\frac{2 \pi}{3}\right) & \cos \left(\theta+\frac{2 \pi}{3}\right) \\ -\sin \theta & -\sin \left(\theta-\frac{2 \pi}{3}\right) & -\sin \left(\theta+\frac{2 \pi}{3}\right)\end{array}\right]$

Where $\theta$ denotes the angular position of $(d q)$ rotating frame with respect to $(a b c)$ stationary frame. It yields:

$$
\begin{aligned}
& L \frac{d i_{d q}}{d t}=-A i_{d q}+v_{D C} u_{d q}-v_{g, d q} \\
& A=\left[\begin{array}{cc}
R & -L \omega \\
L \omega & R
\end{array}\right], \omega=\frac{d \theta}{d t}
\end{aligned}
$$

\section{Sliding Mode Control Design}

The goal of the SMC is to ensure high dynamic tracking performance for the inverter output currents. In the first stage of the control design process, the sliding surface should be chosen according to the desired dynamics in the sliding mode of operation. Once the sliding surface is defined, the reaching control law ensuring system stability on the surface is then developed. Finally, the generated SMC law is transferred as a control signal to be compared with the fixed-frequency ramp of the pulse width modulator.

\section{A. Sliding surface design}

The basic idea of a SM current control is to design a certain sliding surface in its control law that will track the desired state variables towards its desired references. For this purpose two sliding surfaces are introduced in SRF frame; $S_{d}$ for controlling the direct current and $S_{q}$ for the indirect one, whereas $i_{d, r e f}$ and $i_{q, r e f}$ are the $\mathrm{d}$-axis and q-axis reference currents, respectively that should be tracked by the control system.

$$
\begin{aligned}
& S_{d}=i_{d}-i_{d}, r e f \\
& S_{q}=i_{q}-i_{q, r e f}
\end{aligned}
$$

The performance of the SMC is evaluated by the system tracking behavior and especially against disturbances. In order to obtain a sliding mode over a surface a sliding vector where $\sigma$ is presented.

$\sigma=\left[\begin{array}{l}s_{d} \\ s_{q}\end{array}\right]=0$

An equivalent control law $u_{e q}$ that satisfies the condition $\dot{\sigma}=0$ should be elaborated. Therefore, (8) is obtained.

$\dot{\sigma}=\left[\begin{array}{c}\dot{S}_{d}=\dot{i}_{d}-\dot{i}_{d, r e f} \\ \dot{S}_{q}=\dot{i}_{q}-\dot{i}_{q, r e f}\end{array}\right]=0$

The main drawback of the SMC method is the chattering problem that is due to the discontinuity in the control law. Reducing the system chattering remains a challenge in the SMC design. Gao et al have proposed a complete definition for the reaching law that weaken system chattering [37]. In form of equation it can be written by:

$$
\dot{\sigma}=\left[\begin{array}{ll}
-\varepsilon_{d} & \operatorname{sgn}\left(S_{d}\right)-k_{d} S_{d} \\
-\varepsilon_{q} & \operatorname{sgn}\left(S_{q}\right)-k_{q} S_{q}
\end{array}\right] \quad \varepsilon_{\mathrm{d}}, \quad \varepsilon_{\mathrm{q}}>0, k_{\mathrm{d}}, k_{\mathrm{q}}>0(9)
$$

In the presented work, the following assumptions will be considered:

$$
\begin{aligned}
& v_{D C} u_{d}-v_{g d}=-\varepsilon_{d} \operatorname{sgn}\left(s_{d}\right)-k_{d} s_{d}-L \omega i_{q} \\
& v_{D C} u_{q}-v_{g q}=-\varepsilon_{q} \operatorname{sgn}\left(s_{q}\right)-k_{q} s_{q}+L \omega i_{d}
\end{aligned}
$$

Where $\varepsilon_{d}, \varepsilon_{q}, k_{d}, k_{q}$ are the SM control parameters. By computing the derivative of (6) and integrating then equations (4), (5) and (9), the following relations would be attained:

$$
\begin{aligned}
& \dot{S}_{d}=-\frac{1}{L}\left[R S_{d}+\varepsilon_{d} \operatorname{sgn}\left(S_{d}\right)+k_{d} S_{d}+R i_{d, r e f}+L \dot{i}_{d, r e f}\right] \\
& \dot{S}_{q}=-\frac{1}{L}\left[R S_{q}+\varepsilon_{q} \operatorname{sgn}\left(S_{q}\right)+k_{q} S_{q}+R i_{q, r e f}+L \dot{i}_{q, r e f}\right]
\end{aligned}
$$

\section{B. Stability and reaching conditions}

It is evident that the system stability is ensured by the following conditions: 


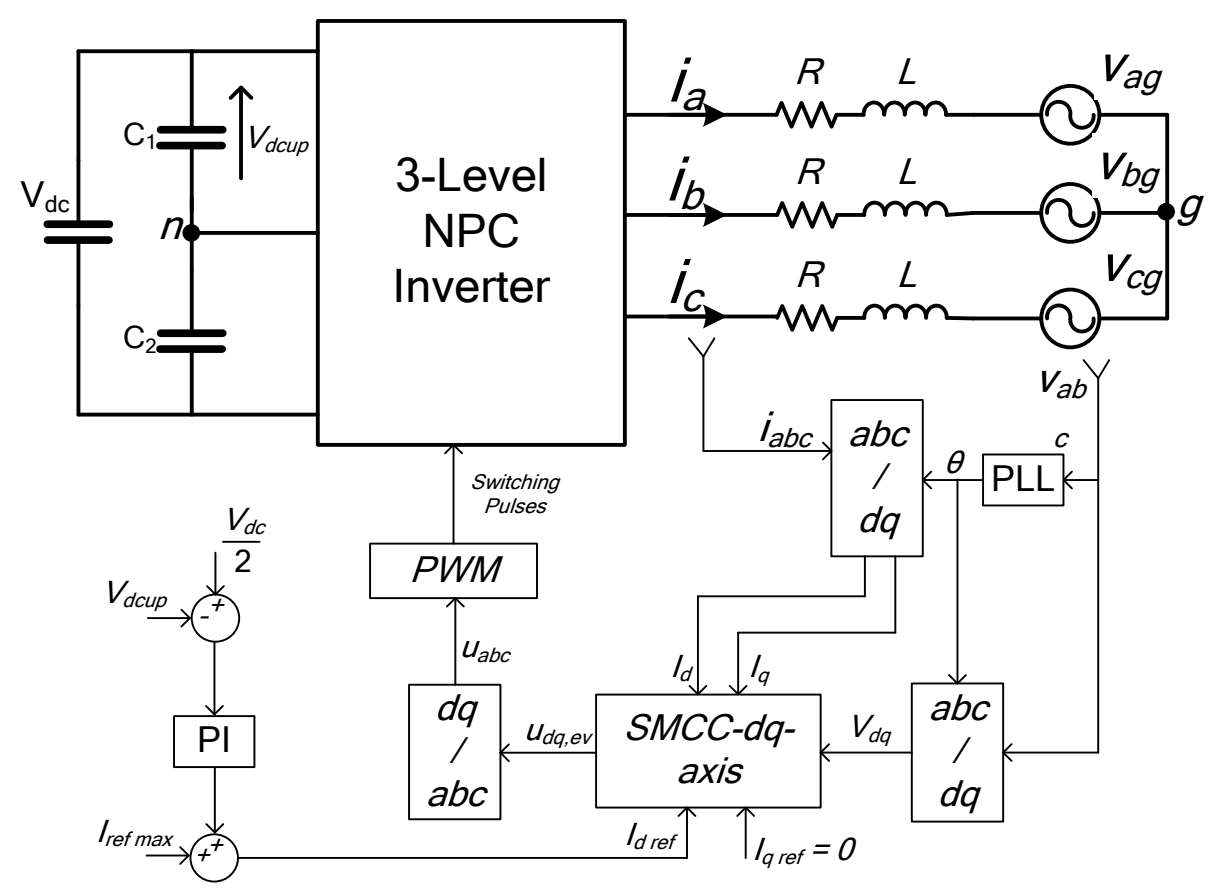

Fig. 2. Control system applied to the grid-connected three-phase/wire/level NPC inverter.

$$
\begin{array}{ll}
S_{d} & \dot{S}_{d}<0 \\
S_{q} & \dot{S}_{q}<0
\end{array}
$$

In terms of functions it can be written as:

$$
\begin{aligned}
& S_{d} \dot{S}_{d}=-\frac{1}{L}\left[\left(R_{d}+k_{d}\right) S_{d}^{2}+S_{d}\left(\varepsilon_{d} \operatorname{sgn}\left(S_{d}\right)+R i_{d}, \text { ref }+L \dot{i}_{d}, \text { ref }\right)\right] \\
& S_{q} \dot{S}_{q}=-\frac{1}{L}\left[\left(R_{q}+k_{q}\right) S_{q}^{2}+S_{q}\left(\varepsilon_{q} \operatorname{sgn}\left(S_{q}\right)+R i_{q, \text { ref }}+L \dot{i}_{q}, \text { ref }\right)\right]
\end{aligned}
$$

Which yields in terms of $\varepsilon_{d}, \varepsilon_{q}, k_{d}$ and $k_{q}$

$$
\begin{aligned}
& k_{d}>0 \\
& k_{q}>0 \\
& \varepsilon_{d}>\left|R i_{d, r e f}+L i_{d, r e f}\right| \\
& \varepsilon_{q}>\left|R i_{q, r e f}+L i_{q, r e f}\right|
\end{aligned}
$$

The non-positivity condition for Lyaponov function $\mathrm{V}$ that ensure the best reaching condition given in (15) is also ensured by the same parameters conditions given by (14).

$$
V=\frac{1}{2}\left(S_{d}^{2}+S_{q}^{2}\right)
$$

The choice of the parameters is very critical for this type of controller. High values of such parameters would increase the chattering problem; while lower values affect the converging process where a narrower band is obtained. A trade-off between these two selection approaches has to be considered. In order to achieve PWM-fixed switching frequency control, a relationship between the SM equivalent control law $u_{e q}$ and the control signal of the PWM modulator should be elaborated. A detailed description about the derivation of PWM-based SM control system by mapping the equivalent control function into a duty cycle function of the PWM modulator is given in [31]. Since the SRF frame has been considered in our proposed work, two equivalent control laws are elaborated $\left(u_{d, e q}, u_{q, e q}\right)$ from equation (10) and therefore a transformation into natural control frame (abc) is applied.

$$
\begin{aligned}
& u_{d, e q}=\frac{1}{V_{D C}}\left[-\varepsilon_{d} \operatorname{sgn}\left(s_{d}\right)-k_{d} s_{d}-L \omega i_{q}+v_{g d}\right] \\
& u_{q, e v}=\frac{1}{V_{D C}}\left[-\varepsilon_{q} \operatorname{sgn}\left(s_{q}\right)-k_{q} s_{q}+L \omega i_{d}+v_{g q}\right]
\end{aligned}
$$

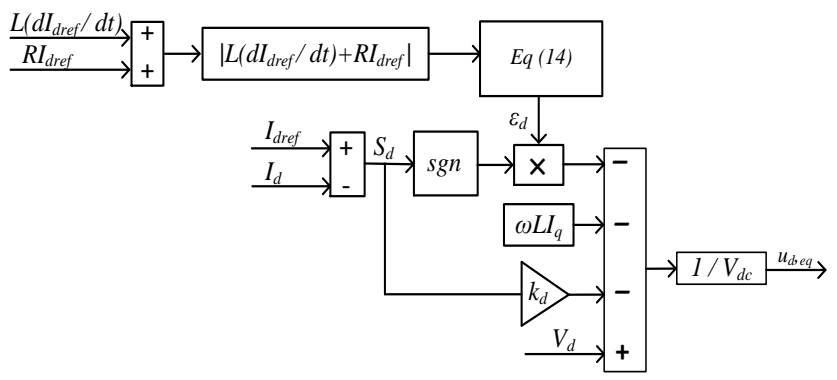

Fig. 3. Sliding Mode Current controller on the d-axis current (SMCC-d-axis) 
A block-diagram of the whole control system is shown in Fig. 2. Since the inverter is connected to the grid, the synchronization with the grid voltages is a matter of importance in the control design. The electrical grid is usually a complex dynamic system. Grid connection requires multiple features for a system to fulfill grid requirements at any time and in an accurate manner, and to respond instantaneously to grid faults. Information on the grid instantaneous state is transferred in real-time to the controller algorithm for synchronization procedure. The main goal of the converter is to inject a line current in phase with the grid voltage to get a unity power factor. So, the value of the grid phase-voltage angle is monitored continuously and used in the transformation matrix (3). Many synchronization methods were introduced for this purpose while the basic PhaseLocked Loop (PLL) technique is adopted in this proposed work. The Sliding mode current controller on d-axis is detailed in Fig. 3. It is noted that the same procedure is adopted for the current controller on q-axis.

As explained earlier, the voltage balancing process remains a drawback in this topology. So, a PI controller has been added in order to maintain the capacitor voltages at equal values which is observable in Fig. 2.

\section{EXPERIMENTAL RESULTS AND DISCUSSION}

A laboratory scale prototype of three-phase/wire/level gridconnected NPC has been implemented in order to validate the proposed sliding mode control scheme. Twelve $1.2 \mathrm{kV}, 35 \mathrm{~A}$ $\mathrm{SiC}$ MOSFETs of type SCT2080KE and $6 \mathrm{SiC}$ fast-recovery clamping diodes of type SCS220KG are employed. The controller is implemented using the DSpace ds1103 real-time controller board with associated I/Os. The adopted sampling time is $22 \mu \mathrm{s}$. The system parameters used for experimentation are given in Table II. Reported results cover both steady state and transient operations of the converter.

Figs. 4 and 5 show the steady operation of the NPC inverter in grid-connected mode while the SMC is controlling the injected current to be in phase with the grid voltage. Three levels phase-to neutral and five levels phase-to-phase inverter output voltages are well obtained.

The five-level symmetrical output voltage of the NPC inverter demonstrates the good dynamic performance of PWM technique leads to have fixed and low switching frequency with low power losses. Moreover, the low voltage ripple of capacitor proves the proper design of the controller in balancing the DC capacitor voltages with less deviation as it is very clear in Fig.5. The grid voltage and current waveforms (from phase a) have also been captured by AEMC power analyser, as illustrated in Fig. 6. It is clear that the power factor is almost 1. Although the source voltage has a THD $3.1 \%$ and the controller takes samples from this voltage waveform, the injected current contains low harmonics such that the THD is only $2.6 \%$ that is still below the accepted limit of IEEE standards.
TABLE II

EXPERIMENTAL SYSTEM PARAMETERS

\begin{tabular}{c|c|c}
\hline \hline Variable & Description & Values \\
\hline \hline$V_{d c}$ & DC bus voltage $(\mathrm{V})$ & 300 \\
$f_{g}$ & Grid Frequency $(\mathrm{Hz})$ & 60 \\
$C_{1}, C_{2}$ & DC-link Capacitance $(\mu \mathrm{F})$ & 650 \\
$L$ & Line inductance $(\mathrm{mH})$ & 5 \\
$v_{x g}(x: a, b, c)$ & Grid $r m s$ phase voltage $(\mathrm{V})$ & 100 \\
$i_{x}(x: a, b, c)$ & Grid rms current $(\mathrm{A})$ & 3.5 \\
$f_{s w}$ & Switching frequency $(\mathrm{kHz})$ & 2 \\
\hline \hline \multicolumn{3}{c}{ Sliding Mode Current Controller Parameters } \\
\hline \hline \multicolumn{2}{c}{ Moxis parameter 1 } & 200 \\
$\varepsilon_{d}$ & d-axis parameter 2 & 100 \\
$k_{d}$ & d-axis & 200 \\
$\varepsilon_{q}$ & q-axis parameter 1 parameter 2 & 50 \\
\hline \hline \multicolumn{2}{c|}{ Proportional Integral (PI) Controller Parameters } \\
\hline \hline$K_{p}$ & Proportional gain $\left(\mathrm{K}_{\mathrm{p}}\right)$ & 0.1 \\
$K_{i}$ & Integral gain $\left(\mathrm{K}_{\mathrm{i}}\right)$ & 0.5 \\
\hline \hline
\end{tabular}

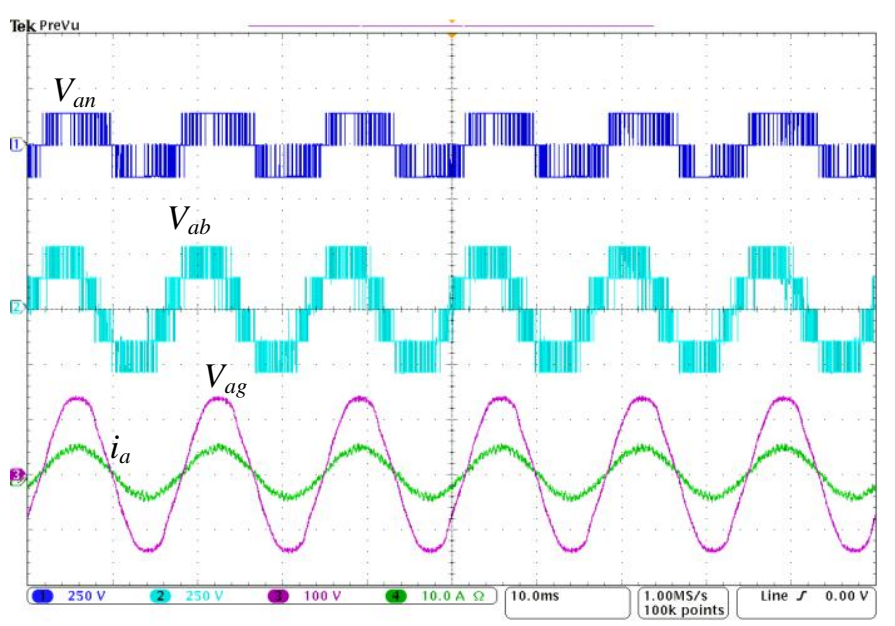

Fig. 4. Steady state voltage and current waveforms for grid connected NPC.

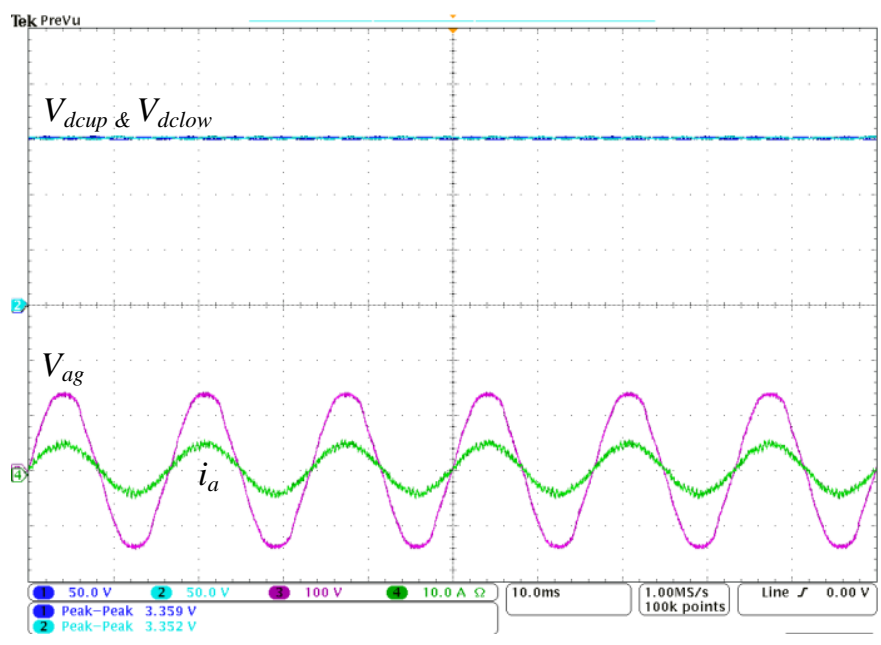

Fig. 5. DC bus voltages and grid side voltage/current waveforms. 


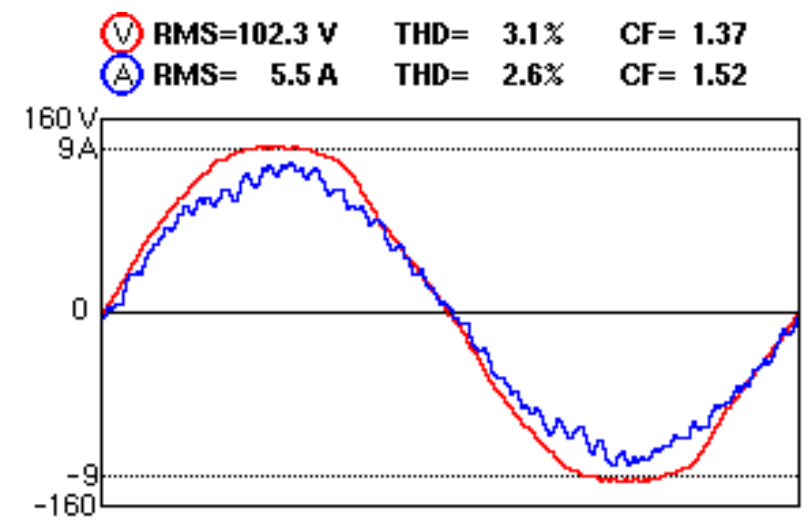

Fig. 6. Grid side voltage and current waveform, RMS values and THD.

It should be mentioned that this low THD has been achieved by firing the switches in only $2 \mathrm{KHz}$, which is significantly less than the similar works in 2-level converters. The low switching frequency makes the multilevel inverters suitable for high power applications especially in renewable energy conversion that needs high efficiency interfaces to deliver power to the grid.

In order to study more the operation of the system with the controller proposed, different tests were adopted to compare the SMC with a conventional PI regulator.

\section{A. Test 1: operation with DC voltage variations}

The main drawback of the 3L-NPC is the balancing between upper and lower capacitors. To study the behavior of the system under DC link variation a DC voltage variation of $30 \mathrm{~V}$ has been applied to the controller as it can be seen in Fig. 7. In Fig. 7.a, the results when the proposed SMC is used are shown while Fig. 7.b shows the results of the PI regulator. The SMC shows better performance of maintaining the balancing between the DC side voltages when the DC side voltage change from $300 \mathrm{~V}$ to $330 \mathrm{~V}$ and returns back to $300 \mathrm{~V}$; lower DC voltage ripples are obtained as well as an accurate tracking to voltage variations.

\section{B. Test 2: operation with grid voltage disturbances}

A variation of $17 \%$ in the $\mathrm{AC}$ voltage amplitude is applied in this case. It is evident that the system operates with a unity power factor under this perturbation. Moreover, the balancing between the DC side voltages is more controlled when a SMC is used as it is shown in Fig. 8.

\section{Test 3: operation with current reference variations}

Moreover, to validate the fast tracking response and good dynamic performance of the designed controller, a change in the current reference value from $5 \mathrm{~A}$ to $8 \mathrm{~A}$ was adopted as it is shown in Fig. 9. It is evident that during the change in injected current amplitude, the controller takes action properly in making it in-phase with grid voltage as well as controlling the capacitors voltages. The change in reference current amplitude has been made during the real-time implementation.

\section{Test 4: operation with reactive power variation}

In order to investigate more the controller introduced, a reactive power test was adopted. A variation in the phase shift of $30^{\circ}$ is applied to the controller during the real-time implementation as it is shown in Fig. 10. It is evident in the zoomed part of Fig. 10, that the controller responds and injects a shifted current to the AC side while maintaining the DC bus voltages equal. It should be noted that the same performance was obtained with the PI regulator.

\section{E. Test 5: THD and power factor versus switching frequency and power variations.}

In order to study better the performance and the robustness of this controller, the operation of the overall grid connected system has been tested for different switching frequencies with the same system parameters shown in table II. As it is presented in Fig. 11 the SMC shows the same performance for higher switching frequencies. A THD current less than 5\% and a high power factor were always attained. From other side, the system operates normally with a conventional PI regulator for switching frequencies less than $6 \mathrm{kHz}$. For higher switching frequencies, the system was not able to stabilize the DC voltages and inject a synchronized current to the grid. A tuning for the PI parameters is requested while the SMC shows a high robustness under switching frequencies variations. Finally, Fig. 12 depicts the results of the system tested in transmitted power variations; the SMC shows a system operation nearby the conventional one in terms of high power factor and low $\mathrm{THD}_{\mathrm{i}}$

\section{CONCLUSION}

In this paper a sliding mode current control technique has been proposed and implemented on a grid connected NPC inverter as renewable energy resources interface to the grid. The main advantage of this technique is that a low THD current is given to the grid with only L filter required. Experimental results that confirm the good dynamic performance of this technique are presented. The overall system shows robustness

against external disturbances at the $\mathrm{DC}$ and $\mathrm{AC}$ sides. Moreover, it shows better performance in stabilizing the DC link voltages than a PI regulator in higher switching frequencies. Not only the robustness and the dynamic response of the system against external perturbations have been verified, but also the ability of the system to inject a synchronized current with low THD and low ripples to the grid has been proved. Eventually, it can be concluded that the presented 3 Phase/Wire/Level NPC inverter using implemented sliding mode controller can be a good candidate. 


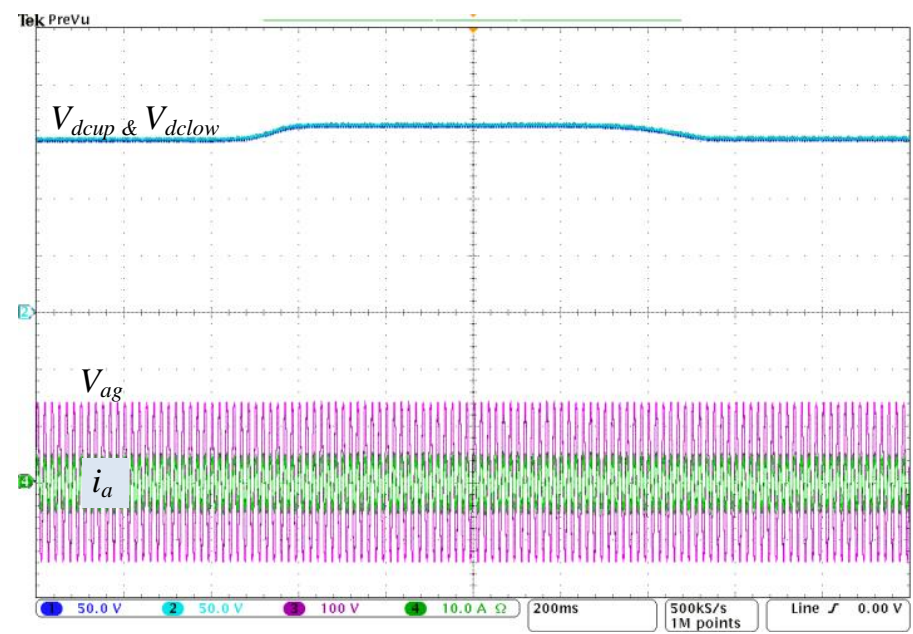

(a)

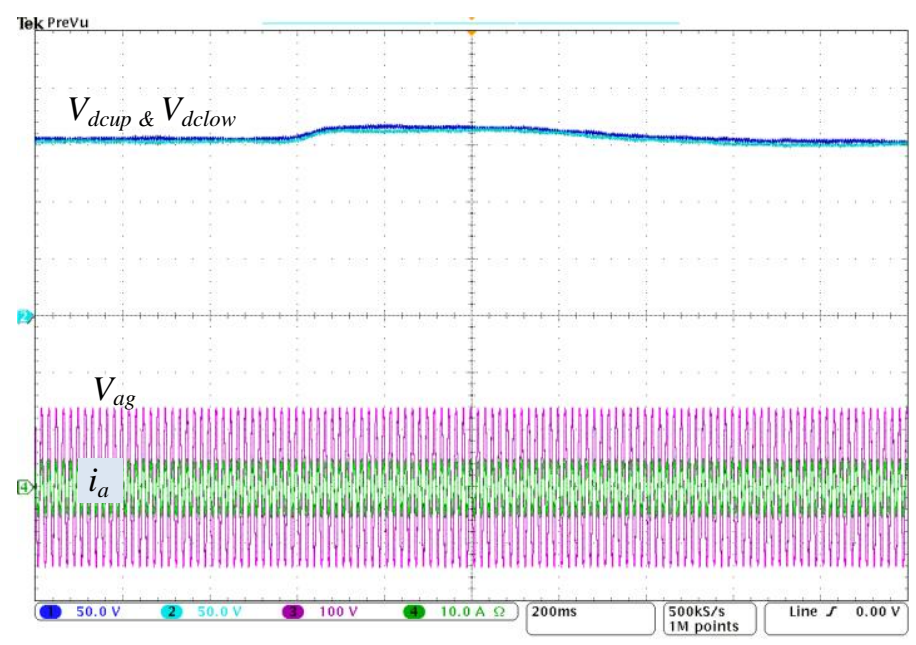

(b)

Fig. 7. DC bus voltage variations between $300 \mathrm{~V}$ and $330 \mathrm{~V}$ (a) SMC. (b) PI

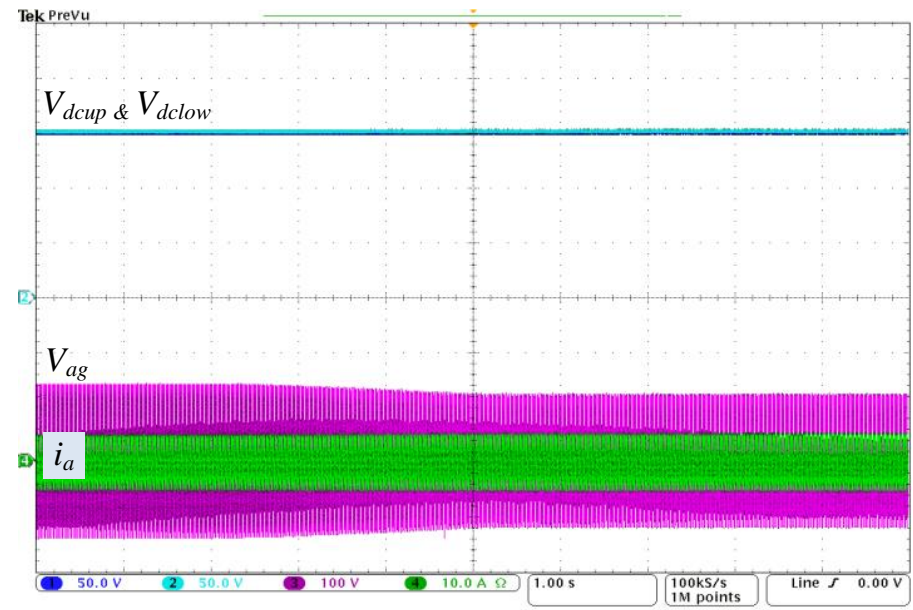

(a)

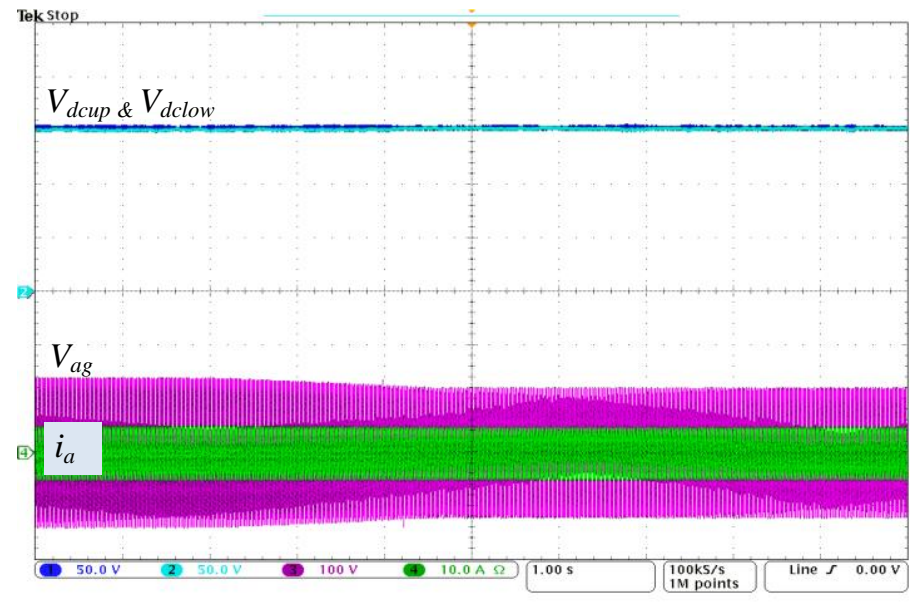

(b)

Fig. 8. AC voltage variation from $100 \mathrm{~V}$ to $83 \mathrm{~V}$. (a) SMC. (b) PI

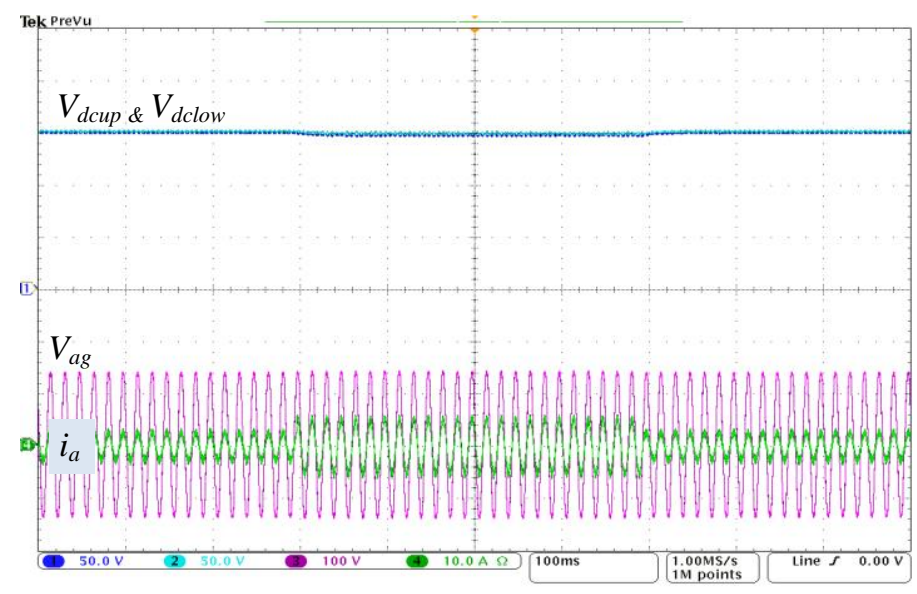

(a)

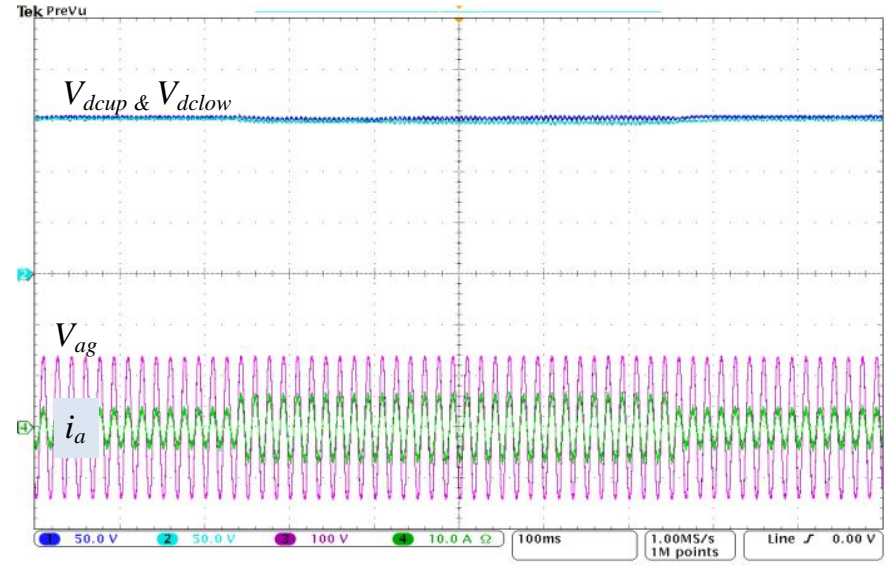

(b)

Fig. 9. System respone to a sudden increase/decrease of reference current. (a) SMC . (b) PI 


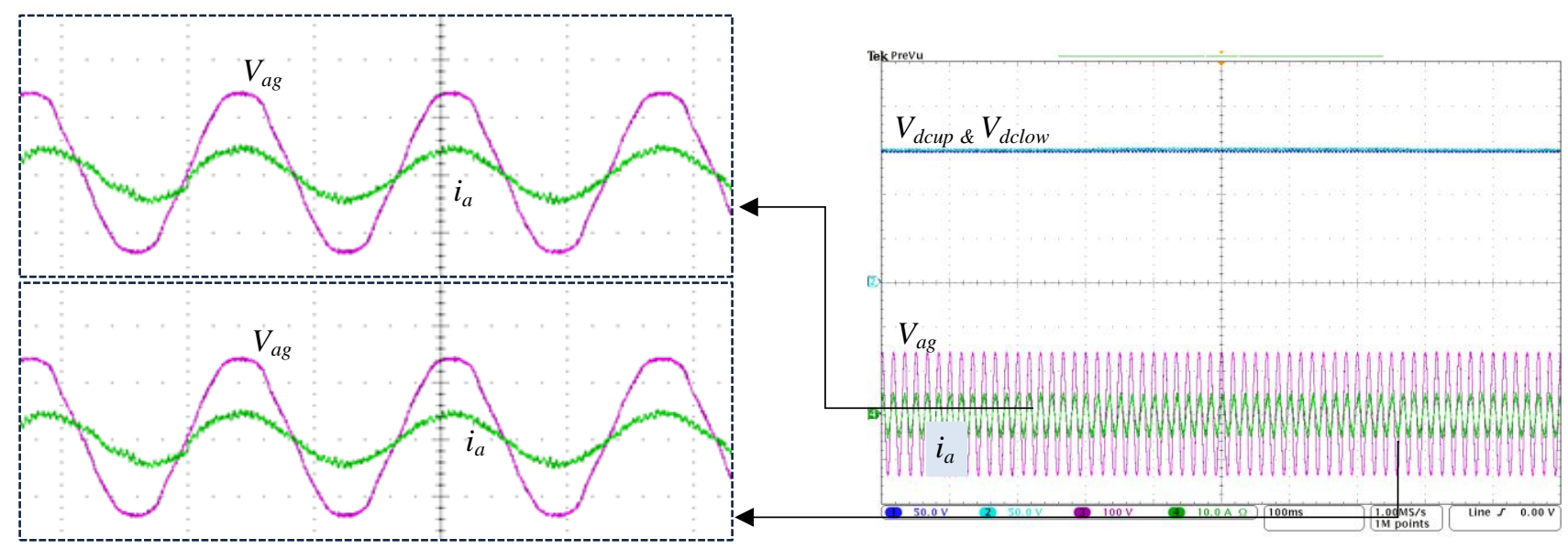

Fig. 10. Phase shift variation between $0^{\circ}$ to $30^{\circ}$.

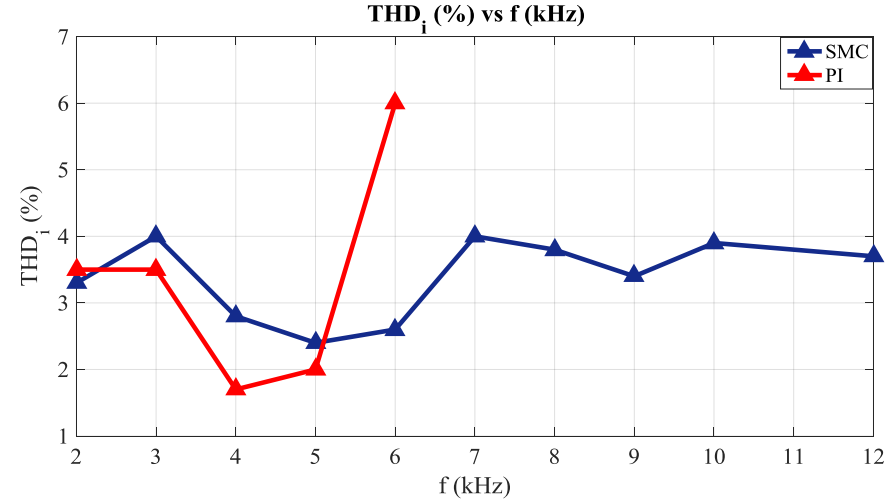

Fig. 11. System operation versus switching frequency variations; $\mathrm{THD}_{\mathrm{i}}$

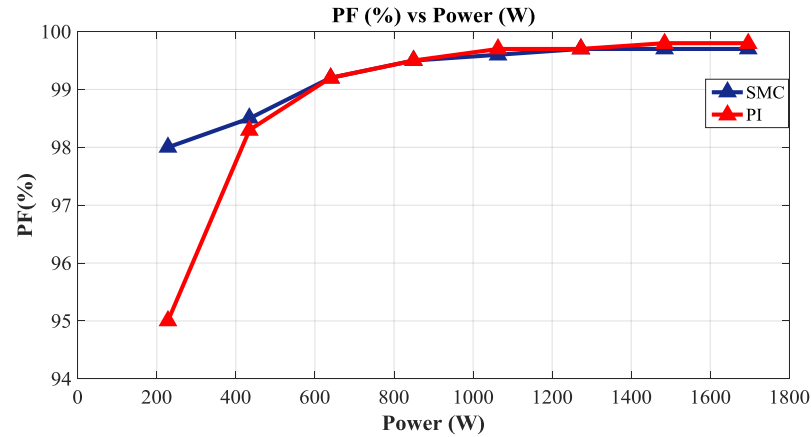

(a)

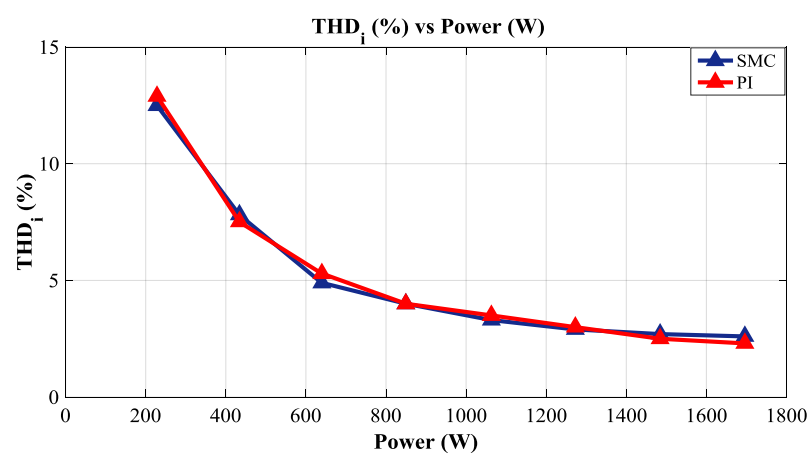

Fig. 12. System operation versus transmitted power. (a) $\mathrm{PF}$ (b) $\mathrm{THD}_{\mathrm{i}}$

\section{REFERENCES}

[1] F. Blaabjerg, Z. Chen, and S. B. Kjaer, "Power electronics as efficient interface in dispersed power generation systems," IEEE Trans on Power.Electron., vol. 19, no. 5, pp. 1184-1194, 2004.

[2] J. M. Carrasco, L. G. Franquelo, J. T. Bialasiewicz, E. Galván, R. C. P. Guisado, M. Á. M. Prats, J. I. León, and N. MorenoAlfonso, "Power-electronic systems for the grid integration of renewable energy sources: A survey," IEEE Trans on Ind. Electron., vol. 53, no. 4, pp. 1002-1016, 2006.

[3] J. Rodriguez, J.-S. Lai, and F. Z. Peng, "Multilevel inverters: a survey of topologies, controls, and applications," IEEE Trans on Ind. Electron., vol. 49, no. 4, pp. 724-738, 2002.

[4] M. Sharifzadeh, H. Vahedi, R. Portillo, M. Khenar, A. Sheikholeslami, L. G. Franquelo, and K. Al-Haddad, "Hybrid SHM-SHE Pulse Amplitude Modulation for High Power FourLeg Inverter," IEEE Trans. Ind. Electron., vol. PP, no. 99, pp. 1-1, 2016.

[5] L. G. Franquelo, J. Rodriguez, J. I. Leon, S. Kouro, and R. Portillo, "The age of multilevel converters arrives," IEEE Ind. Electron. Magazine, vol. 2, no. 2, pp. 28-39, 2008.

[6] H. Vahedi, A. Chandra, and K. Al-Haddad, "Five-Level ReducedSwitch-Count Boost PFC Rectifier with Multicarrier PWM," in ECCE 2015-Energy Conversion Congress \& Exposition, Canada, 2015, pp. 2413-2420.

H. Vahedi, P. Labbe, and K. Al-Haddad, "Sensor-Less Five-Level Packed U-Cell (PUC5) Inverter Operating in Stand-Alone and Grid-Connected Modes," IEEE Trans. Ind. Informat., vol. 12, no. 1, pp. 361-370, 2016. 
[8] H. Vahedi and K. Al-Haddad, "A Novel Multilevel Multi-Output Bidirectional Active Buck PFC Rectifier," IEEE Trans. Ind. Electron., vol. PP, no. 99, pp. 1-1, 2016.

[9] A. Nabae, I. Takahashi, and H. Akagi, "A new neutral-pointclamped PWM inverter," IEEE Trans on Ind. Inform., no. 5, pp. 518-523, 1981.

[10] T. Meynard and H. Foch, "Multi-level conversion: high voltage choppers and voltage-source inverters," in Power Electronics Specialists Conference, 1992. PESC'92 Record., 23rd Annual IEEE, 1992, pp. 397-403.

[11] F. Z. Peng, J.-S. Lai, J. W. McKeever, and J. VanCoevering, "A multilevel voltage-source inverter with separate DC sources for static var generation," IEEE Trans on ind. Inform., vol. 32, no. 5, pp. 1130-1138, 1996.

[12] S. Alepuz, S. Busquets-Monge, J. Bordonau, J. Gago, D. González, and J. Balcells, "Interfacing renewable energy sources to the utility grid using a three-level inverter," IEEE Trans on Ind. Electron., vol. 53, no. 5, pp. 1504-1511, 2006.

[13] F. Sebaaly, H. Vahedi, H. Y. Kanaan, N. Moubayed, and K. AlHaddad, "Finite control set model predictive controller for grid connected inverter design," in 2016 IEEE International Conference on Industrial Technology (ICIT), 2016, pp. 12081213.

[14] F. Sebaaly, H. Vahedi, H. Kanaan, N. Moubayed, and K. AlHaddad, "Design and Implementation of Space Vector Modulation Based Sliding Mode Control for Grid-Connected 3LNPC Inverter," IEEE Trans. on Ind. Electron., vol. PP, no. 99, pp. 1-1, 2016.

[15] R. C. Portillo, M. M. Prats, J. A. Sánchez, J. M. Carrasco, E. Galván, and L. G. Franquelo, "Modeling strategy for back-to-back three-level converters applied to high-power wind turbines," IEEE Trans on Ind. Electron., vol. 53, no. 5, pp. 1483-1491, 2006.

[16] F. Sebaaly, H. Y. Kanaan, and N. Moubayed, "Three-level neutral-point-clamped inverters in transformerless PV systemsState of the art," in Mediterranean Electrotechnical Conference (MELECON), 2014 17th IEEE, 2014, pp. 1-7.

[17] F. Sebaaly, H. Y. Kanaan, and N. Moubayed, "A Comparative Evaluation of Conventionnal and Supercapacitors in GridConnected Transformerless PV Systems," in Emerging Technology and Factory Automation (ETFA), 2014 IEEE, 2014, pp. 1-7.

[18] H. Vahedi, P.-A. Labbé, and K. Al-Haddad, "Balancing ThreeLevel NPC Inverter DC Bus Using Closed-Loop SVM: Real Time Implementation and Investigation," IET Power Electronics, vol. PP, no. 99, pp. 1-1, 2016.

[19] M. P. Kazmierkowski and L. Malesani, "Current control techniques for three-phase voltage-source PWM converters: a survey," IEEE Trans on Ind. Electron., vol. 45, no. 5, pp. 691703, 1998.

[20] C. Edwards and S. Spurgeon, Sliding mode control: theory and applications: CRC Press, 1998.

[21] V. Utkin, J. Guldner, and J. Shi, Sliding mode control in electromechanical systems vol. 34: CRC press, 2009.

[22] K. D. Young, V. I. Utkin, and U. Ozguner, "A control engineer's guide to sliding mode control," IEEE transactions on control systems technology, vol. 7, no. 3, pp. 328-342, 1999.

[23] V. I. Utkin, "Sliding mode control design principles and applications to electric drives," IEEE Trans on Ind. Electron., vol. 40, no. 1, pp. 23-36, 1993.

[24] C. Lascu, I. Boldea, and F. Blaabjerg, "Direct torque control of sensorless induction motor drives: a sliding-mode approach," IEEE Trans on Ind. Applic., vol. 40, no. 2, pp. 582-590, 2004.

[25] B. Beltran, T. Ahmed-Ali, and M. Benbouzid, "High-order sliding-mode control of variable-speed wind turbines," IEEE Trans on Ind. Electron., vol. 56, no. 9, pp. 3314-3321, 2009.

[26] B. Beltran, T. Ahmed-Ali, and M. E. H. Benbouzid, "Sliding mode power control of variable-speed wind energy conversion systems," IEEE Trans on Ener. Conv., vol. 23, no. 2, pp. 551-558, 2008.
[27] G. Park and Z. Gajic, "A simple sliding mode controller of a fifthorder nonlinear PEM fuel cell model," IEEE Trans on Ener. Conv., vol. 29, no. 1, pp. 65-71, 2014.

[28] B. J. Cardoso, A. Moreira, B. Menezes, and P. Cortizo, "Analysis of switching frequency reduction methods applied to sliding mode controlled DC-DC converters," in Applied Power Electronics Conference and Exposition, 1992. APEC'92. Conference Proceedings 1992., Seventh Annual, 1992, pp. 403-410.

[29] V. M. Nguyen and C. Lee, "Tracking control of buck converter using sliding-mode with adaptive hysteresis," in Power Electronics Specialists Conference, 1995. PESC'95 Record., 26th Annual IEEE, 1995, pp. 1086-1093.

[30] R. Guzman, L. Garcia de Vicuna, J. Morales, M. Castilla, and J. Matas, "Sliding-Mode Control for a Three-Phase Unity Power Factor Rectifier Operating at Fixed Switching Frequency," IEEE Trans. on Power. Electron., vol. 31, no. 1, pp. 758-769, 2016.

[31] S.-C. Tan, Y. Lai, C. K. Tse, and M. K. Cheung, "A fixedfrequency pulsewidth modulation based quasi-sliding-mode controller for buck converters," IEEE Trans on Power.Electron., vol. 20, no. 6, pp. 1379-1392, 2005.

[32] A. Abrishamifar, A. A. Ahmad, and M. Mohamadian, "Fixed switching frequency sliding mode control for single-phase unipolar inverters," IEEE Trans on Power. Electron., vol. 27, no. 5, pp. 2507-2514, 2012.

[33] H. Erdem, "Comparison of fuzzy, PI and fixed frequency sliding mode controller for DC-DC converters," in Electrical Machines and Power Electronics, 2007. ACEMP'07. International Aegean Conference on, 2007, pp. 684-689.

[34] J. Hu, L. Shang, Y. He, and Z. Zhu, "Direct active and reactive power regulation of grid-connected DC/AC converters using sliding mode control approach," IEEE Trans on Power. Electron., vol. 26, no. 1, pp. 210-222, 2011.

[35] W. Wang, H. Yin, and L. Guan, "A direct power control scheme for three-phase PWM rectifiers based on sliding-mode variable structure control theory," in 2009 International Conference on Power Electronics and Drive Systems (PEDS), 2009.

[36] S. Huseinbegovic and B. Perunicic-Drazenovic, "A sliding mode based direct power control of three-phase grid-connected multilevel inverter," in Optimization of Electrical and Electronic Equipment (OPTIM), 2012 13th International Conference on, 2012, pp. 790-797.

[37] W. Gao, Y. Wang, and A. Homaifa, "Discrete-time variable structure control systems," Industrial Electronics, IEEE Transactions on, vol. 42, no. 2, pp. 117-122, 1995.

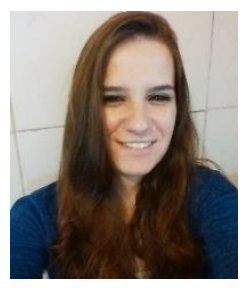

Fadia Sebaaly (S'14) was born in Beirut, Lebanon, in 1986. She received her B.Sc. and M.Sc. degrees both in electrical engineering from the Lebanese University, Faculty of Engineering (II)-Beirut, Lebanon in 2009 and Saint Joseph University, Faculty of Engineering-ESIB, Beirut, Lebanon in 2012, respectively.

She is currently pursuing her $\mathrm{PhD}$ at Saint Joseph University, Faculty of Engineering-ESIB, Beirut, Lebanon and Doctoral School of Science and Technology, Lebanese University, Beirut, Lebanon. In summer 2014 \& 2015 she was a trainee in Groupe de Recherche en Électronique de Puissance et Commande Industrielle (GRÉPCI), École de Technologie Superieure (ÉTS), in Montreal, Canada. Her research interests include power electronics multilevel converters topology, control (predictive and sliding mode controllers) and modulation techniques, power quality, and their applications into renewable energy systems. 


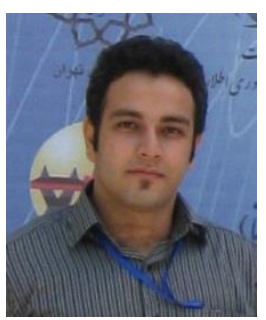

Hani Vahedi (S'10) was born in Sari, IRAN, in 1986. He received his B.Sc. and M.Sc. degrees both in electrical engineering from K. N. Toosi University of Technology (KNTU), Tehran, IRAN in 2008 and Babol University of Technology, Babol, IRAN in 2011, respectively.

$\mathrm{He}$ is currently pursuing his $\mathrm{PhD}$ at the École de Technologie Superieure (ÉTS), University of Quebec, in Montreal, Canada, as a member of Groupe de Recherche en Électronique de Puissance et Commande Industrielle (GRÉPCI). His research interests include power electronics multilevel converters topology, control and modulation techniques, power quality, active power filter, and their applications into smart grid, renewable energy conversion, UPS, battery chargers and electric vehicles. He is an active member of IEEE Industrial Electronics Society and its Student \& Young Professionals committee.

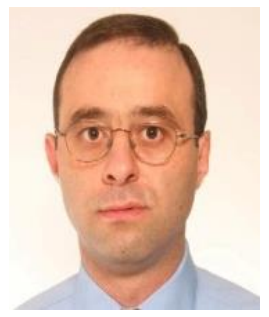

Hadi Y. Kanaan (S'99-M'02-SM'06) received the diploma in electromechanical engineering from Saint-Joseph University of Beirut in 1991, and the Ph.D. degree in electrical engineering from the Ecole de Technologie Supérieure (ETS), Montreal, Canada, in 2002. He is currently a Full-Professor at Saint-Joseph University of Beirut, which he joined in 2001. He is a visiting researcher at ETS since 2004, and associate member of the Canada Research Chair in Energy Conversion and Power Electronics since 2001. His research interests concern modeling and control of switch-mode converters, modern rectifiers, power factor correction, active power filters, and grid-connectivity of renewable energy systems. He is an author of 1 book, 2 book chapters, and more than 170 technical papers published in international journals and conferences. He is an Associate Editor of the IEEE Trans. Industrial Electronics, and member of the IEEE Power Electronics Society (PELS), Industrial Electronics Society (IES) and Industry Applications Society (IAS).

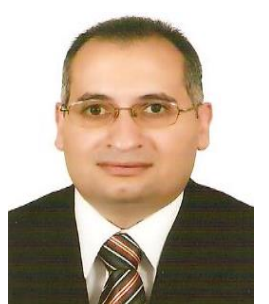

Nazih Moubayed (S'96-M'99-SM'09) got his Diploma of Engineering in Electricity and Electronics (1995) from the Lebanese University (UL), then, in Electrical Engineering, he got his Master (1996) from the Polytechnic National Institute of Toulouse (INPT), his PhD (1999) from the Polytechnic National Institute of Lorraine (INPL) and his and HDR (2011) from UL. Since 1999, he joined the Faculty of Engineering at UL as associate Professor, then, in 2014 he became Professor. He is IEEE Senior Member and associated with other engineering societies. He organized and participates in many conferences. He is reviewer in different international journals and conferences, and, participated in international research projects. He has authored more than 150 papers published in scientific journals, conferences and books. He had supervised more than 34 Eng., $9 \mathrm{MSc}$ and $5 \mathrm{PhD}$ students. His current researches interests are in the area of power electronics, diagnosis of converter-machine set and energy management power systems.

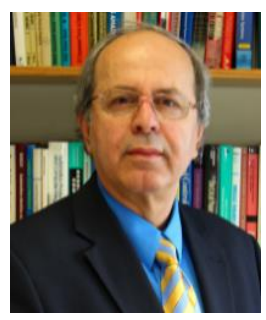

Kamal Al-Haddad (S'82-M'88-SM'92-F'07) received the B.Sc.A. and M.Sc.A. degrees from the University of Québec à Trois-Rivières, Canada, in 1982 and 1984, respectively, and the Ph.D. degree from the Institute National Polythechnique, Toulouse, France, in 1988. Since June 1990, he has been a Professor with the Electrical Engineering Department, École de Technologie Supérieure (ETS), Montreal, QC, where he has been the holder of the Canada Research Chair in Electric Energy Conversion and Power Electronics since 2002. He has supervised more than $100 \mathrm{Ph} . \mathrm{D}$. and M.Sc.A. students working in the field of power electronics. $\mathrm{He}$ is a Consultant and has established very solid link with many Canadian industries working in the field of power electronics, electric transportation, aeronautics, and telecommunications. He has coauthored more than 500 transactions and conference papers. His fields of interest are in high efficient static power converters, harmonics and reactive power control using hybrid filters, switch mode and resonant converters including the modeling, control, and development of prototypes for various industrial applications in electric traction, renewable energy, power supplies for drives, telecommunication, etc. Prof. Al-Haddad is a fellow member of the Canadian Academy of Engineering. He is IEEE IES President 2016-2017, Associate editor of the Transactions on Industrial Informatics, IES Distinguished Lecturer and recipient of the Dr.-Ing. Eugene Mittelmann Achievement Award. 